\title{
Mechanical and Morphological Properties of Recycled High-Density Polyethylene, Filled with Calcium Carbonate and Fly Ash
}

\author{
U. Atikler, D. Basalp, F. Tihminlioğlu \\ Department of Chemical Engineering, Faculty of Engineering, İzmir Institute of Technology, Gülbahçe Köyü, \\ Urla/Izmir 35437, Turkey
}

Received 22 July 2005; accepted 15 May 2006

DOI 10.1002/app.24772

Published online in Wiley InterScience (www.interscience.wiley.com).

\begin{abstract}
In this study, mechanical and morphological properties of composites made up of recycled highdensity polyethylene (HDPE) filled with calcium carbonate and fly ash (FA) were studied. Interfacial interactions were modified to improve the filler compatibility and mechanical properties of the composites by surface treatment of the FA filler with 3-amino propyl triethoxy silane. The composites were prepared by using a Thermo Haake Rheomixer. Effect of filler loading and treatment of FA with silane coupling agent on mechanical and morphological properties were investigated and it was found that sil-
\end{abstract}

ane treatment indicated significant improvements on the mechanical properties of the HDPE-FA composites. The improvement with silane treatment of FA was also confirmed by applying the Pukanszky model. Scanning electron microscopy on the fracture surface of composites had given direct evidence of better interfacial adhesion via silane treatment. () 2006 Wiley Periodicals, Inc. J Appl Polym Sci 102: 4460-4467, 2006

Key words: recycling; composite; fly ash; calcium carbonate; adhesion

\section{INTRODUCTION}

Plastic recycling has attracted more and more attention in the past decade because of the ecological and environmental requirements. Wastes of recyclable materials like paper, plastic, glass, and metal would rather be used as raw materials instead of being buried in disposal areas. In this manner, use of recycled materials will reduce the quantities sent to landfills, as well as reducing raw material extraction. Post consumer plastic waste consists of a wide variety of polymer types. The largest fraction of waste is mainly composed of polyolefins, such as $\mathrm{PE}$ and $\mathrm{PP}(60-70 \%)$ and the remaining include PS (10-15\%), PVC (15\%), and PET $(5 \%){ }^{1}$

The main problems in post consumer recycling are due to the degradation undergone during lifetime and processing steps. The properties-reprocessing relationships are an important tool for determining not only the properties of recycled polymers, but also strategies to apply for obtaining recycled polymers with good mechanical properties. Stabilizers and antioxidants are employed in this manner to improve the mechanical properties. ${ }^{2-4}$ Heterogeneous recycling (poly-

Correspondence to: F. Tihminlioğlu (fundatihminlioglu@ iyte.edu.tr).

Journal of Applied Polymer Science, Vol. 102, 4460-4467 (2006) C 2006 Wiley Periodicals, Inc. mer blend recycling) is also another issue under study for potential use of waste plastics. ${ }^{5,6}$

Different fillers are introduced into polymer matrices to decrease manufacturing cost and to develop mechanical properties. The most important problem encountered in polymer composites is the incompatibility between hydrophilic fillers and hydrophobic polymer matrix. This incompatibility causes poor adhesion between filler and matrix, which in turn causes poor load transfer between them. Mechanical properties are adversely affected by this phenomenon. Various coupling agents are employed to improve adhesion between filler and matrix, depending on the type of filler and matrix. Silane coupling agents have a potential to increase mechanical properties of composites where fillers such as fly ash (FA), cellulose-based fibers, or zeolite are incorporated into matrices such as virgin or recycled high-density polyethylene (HDPE), $\mathrm{PP}$, or LDPE. ${ }^{7-10}$ Titanate coupling agents also find application in calcium carbonate (CC)-thermoplastic composites. ${ }^{5}$

CC is the most widely used filler in thermoplastics because of its low cost and superior mechanical properties. Much effort has been driven to increase mechanical properties such as tensile and flexural strength, impact resistance of CC-filled PP, HDPE, LDPE, and LLDPE composites. ${ }^{2,5,11-13}$

FA is a promising candidate as a filler to incorporate into recycled thermoplastic matrices, since it is also a waste product. Incorporation of FA into PET enhances 
compression properties of PET, which makes FAthermoplastic composites a viable choice for structural parts and concrete industry. ${ }^{10}$ Employing FA in virgin thermoplastic matrices such as PP, HDPE, and LDPE as a filler to replace conventional fillers also gave promising results in terms of tensile properties. ${ }^{7,14}$

In this study, the objective was to determine mechanical properties of FA-filled waste HDPE and compare these properties with a conventional filler, CC. It is expected to make use of waste materials in new areas by obtaining novel composite materials with developed mechanical properties and characteristics.

\section{THEORY}

Interfacial adhesion of the components in filled polymers can be deduced from mechanical properties of composites with the help of models describing composition dependence. Such models must also take into account the interfacial interactions. One of these models considers interface thickness and yield stress of composites as the key parameters and defines a parameter related to stress transfer between components. Semiempirical equation was developed for the quantitative description of the composition dependence of tensile yield stress in heterogeneous polymer systems. $^{15}$

$$
\sigma_{\mathrm{yc}} / \sigma_{\mathrm{ym}}=\frac{1-\Phi_{f}}{1+2.5 \Phi_{f}} \exp \left(B_{\sigma \mathrm{y}} \Phi_{f}\right)
$$

where $\Phi_{f}$ is the volume fraction of the filler, and $\sigma_{\mathrm{yc}}$ and $\sigma_{\mathrm{ym}}$ denote the tensile yield stress of composite and matrix, respectively. The first term in eq. (1) is related to the decrease in effective load bearing cross section, while the second one is concerned with the interfacial interaction between filler and matrix. Interfacial interaction depends on the area of the interphase and the strength of the interaction as shown in eq. (2).

$$
B_{\sigma}=\left(1+A_{f} \rho_{f} t\right) \ln \left(\sigma_{\mathrm{yi}} / \sigma_{\mathrm{ym}}\right)
$$

where $A_{f}$ is the specific surface area of the filler, $\rho_{f}$ is its density, and $t$ is the thickness of the interface. From the $B_{\sigma}$ values, strength of interaction $\sigma_{\mathrm{yi}}$ can be calculated.

\section{EXPERIMENTAL}

\section{Materials}

Post consumer recycled and crushed HDPE milk bottles were obtained from commercial sources. CC was received from Sigma and used as received. Particle size of CC was 5-15 $\mu \mathrm{m}$. FA was obtained from a coal-fired power plant in Soma, Turkey. FA was sieved through $106 \mu \mathrm{m}$ sieve before use. Both fillers were then dried at $70^{\circ} \mathrm{C}$ for $24 \mathrm{~h}$ before using as filler in HDPE polymer. FA was modified using surface modifier, 3-amino propyl triethoxy silane (Aldrich), to improve the compatibility of FA with HDPE.

\section{Surface treatment of filler}

Surface modification of FA with silane coupling agent was carried out in solution. Aqueous ethyl alcohol solution $(95 / 5 \mathrm{w} / \mathrm{v})$ was prepared and silane coupling agent $(1 \% \mathrm{w} / \mathrm{w}$ of filler) was added to the solution. The solution was mixed with a mechanical mixer for $15 \mathrm{~min}$ for hydrolysis reaction of silane coupling agent. Then the FA filler was added to the solution of silane coupling agent and left for 45 min under agitation. Afterwards, the solution was introduced into a rotary evaporator at $60^{\circ} \mathrm{C}$ under vacuum for $1 \mathrm{~h}$ until filler was dried. Employment of rotary evaporator prevented agglomeration of particles via rotation action. The filler was further dried in an oven at $70^{\circ} \mathrm{C}$ for $24 \mathrm{~h}$ before composite preparation.

\section{Composite preparation}

Recycled HDPE composites were prepared using a Thermo Haake Rheomixer. Rheological properties, stabilization time, and energy requirement for the mixing could be determined by this equipment. The composites were prepared at mixing temperature of $160^{\circ} \mathrm{C}$, rotor speed of $50 \mathrm{rpm}$, and mixing time of $10 \mathrm{~min}$. First, HDPE was incorporated into the plastograph, and then previously dried fillers were introduced as soon as torque indicated melting of the polymer (about $1.5 \mathrm{~min}$ ). Ten minutes of mixing was enough to reach to the stabilization torque, which indicates homogeneous mixing of filler and matrix. Composites were prepared at $10,20,30$, and $40 \%(\mathrm{w} / \mathrm{w})$ filler loading. The specimens taken from the plastograph were compression-molded in a Carver polymer press into $150 \times 150 \times 1 \mathrm{~mm}^{3}$ rectangular sheets. Composites were heated to $160^{\circ} \mathrm{C}$ without pressure to avoid void and bubble formation and then pressed at 2000 psi pressure at the same temperature for $4 \mathrm{~min}$. The specimens were cooled to $40^{\circ} \mathrm{C}$ in 4 min under pressure.

\section{Mechanical properties}

Tensile tests were carried out on a Testometric mechanical testing machine equipped with a $100 \mathrm{kgf}(\sim 1$ $\mathrm{kN}$ ) load cell. Tests were carried out according to ASTM D 638 (Type IV) at a crosshead speed of $50 \mathrm{~mm} /$ min. Tensile test specimens were prepared using a dog bone-shaped hollow die punch according to the ASTM D 638 standard. A minimum of five specimens for each composition were tested, and the mean values and standard deviations were reported. 
TABLE I

Elemental Analysis of Fly Ash

\begin{tabular}{lrr}
\hline Element & Wt $\%$ & At \% \\
\hline $\mathrm{C}$ & 7.96 & 14.00 \\
$\mathrm{O}$ & 35.10 & 46.33 \\
$\mathrm{Al}$ & 15.70 & 12.29 \\
$\mathrm{Si}$ & 24.76 & 18.62 \\
$\mathrm{~K}$ & 5.98 & 3.23 \\
$\mathrm{Ca}$ & 10.50 & 5.53 \\
Total & 100.00 & 100.00 \\
\hline
\end{tabular}

\section{Morphological properties}

Fracture surface of fractured tensile specimens were investigated by Philips XL 305FEG scanning electron microscope (SEM). Fracture surface of specimens were placed in vertical direction normal to the direction of electron beam. Bonding between filler and matrix, and dispersion of filler in the matrix are determined. Elemental analysis on the surface of FA particles was also made by EDX analysis to determine composition of FA particles.

\section{RESULTS AND DISCUSSION}

\section{Characterization of FA}

Chemical composition of FA was determined by EDX analysis, on the surface of FA particles for at least five points and the results are shown in Table I on weight and atomic percent basis. It has to be noted that $\mathrm{Al}$, $\mathrm{Si}, \mathrm{K}$, and Ca exist in oxide forms in FA, since FA is a waste product of coal burned at high temperature. Corresponding oxide forms are $\mathrm{Al}_{2} \mathrm{O}_{3}, \mathrm{SiO}_{2}, \mathrm{~K}_{2} \mathrm{O}$, and $\mathrm{CaO}$. There also exists unburned carbon in the FA particles.

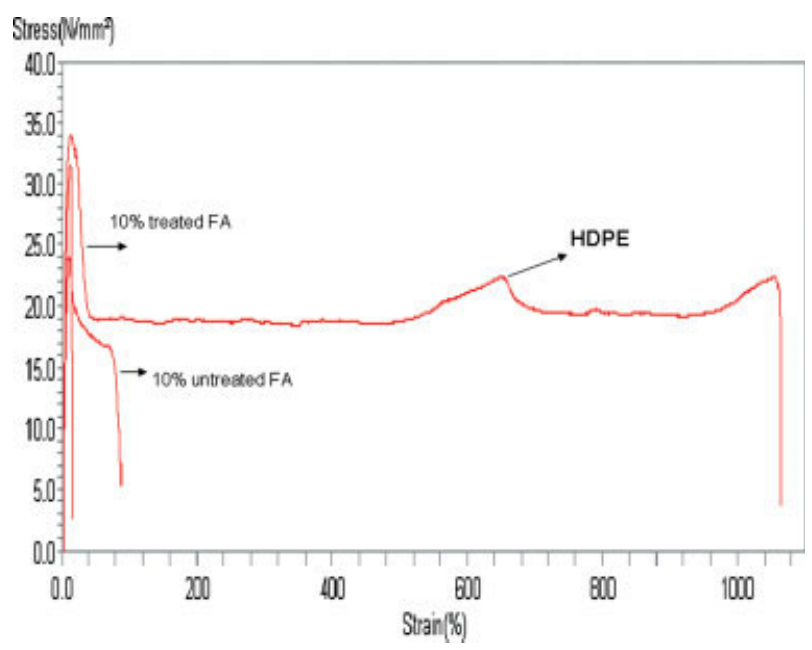

Figure 1 A sample stress-strain data of HDPE and $10 \mathrm{wt}$ $\%$ FA-filled HDPE composites. [Color figure can be viewed in the online issue, which is available at www.interscience. wiley.com.]

\section{Mechanical properties}

Tensile tests of recycled HDPE, and FA- and CC-filled HDPE composites were conducted to determine how the mechanical properties were influenced by the presence of filler and surface modifier.

Tensile strength, elongation at break, and Young's modulus are the most important tensile mechanical properties for polymeric materials. Filler type and content, particle size distribution and shape, mixing conditions and bonding between filler and matrix are important parameters that determine mechanical properties.

Figures 1 and 2 illustrate the stress-strain data of HDPE, and untreated and treated FA-filled HDPE composites (10 and $40 \mathrm{wt} \%$ filler loadings). As seen, incorporation of FA decreased the tensile strength as well as toughness and strain at break of the composites. Young's modulus of the composites tended to increase with the incorporation of FA as observed in the figures. The increase in Young's modulus of the composites was much more pronounced for the treated composites. Strain at break values of the treated composites have decreased compared to the untreated ones.

Figure 3 shows the effect of surface treatment and the composition dependence of tensile strength of CCand FA-filled composites. Tensile strengths of both CC- and FA-filled composites show a decreasing trend as the filler loading increases. This decrease can be explained by stress concentrations that initiate cracks around filler particles.

When tensile strengths of HDPE composites reinforced with untreated FA and CC were compared, it was clearly observed that FA has slightly higher tensile strength than CC at all filler loadings. The decrease in tensile strength of the composites is 40.3 and $34.3 \%$ for $\mathrm{CC}$ and untreated FA, respectively, at $40 \mathrm{wt} \%$ filler loading. However, the reduction in the tensile strength

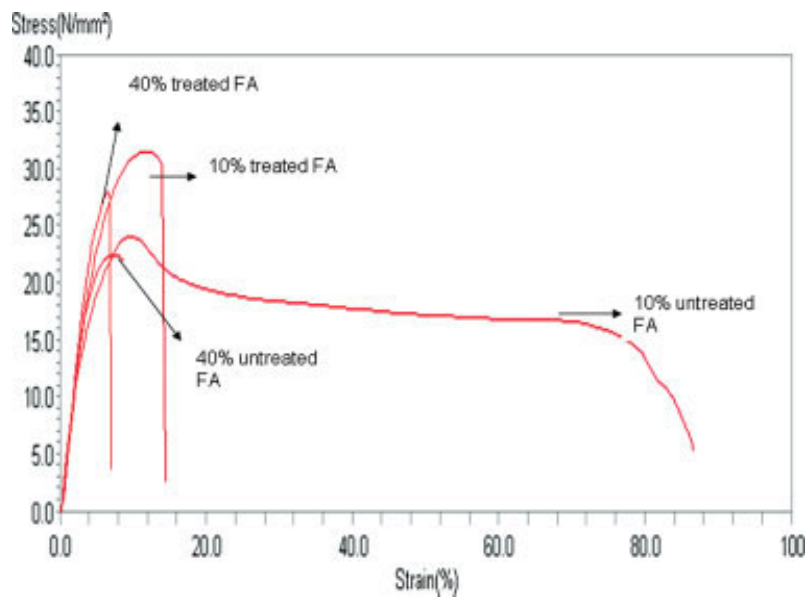

Figure 2 Comparison of the stress-strain curves of 10 and $40 \mathrm{wt} \%$ untreated and treated FA composites. [Color figure can be viewed in the online issue, which is available at www.interscience.wiley.com.] 


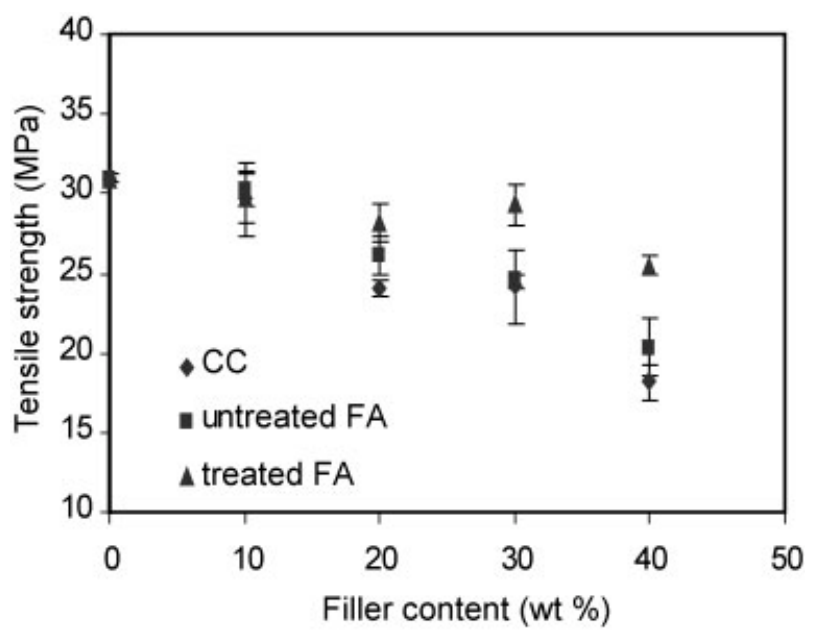

Figure 3 Variation of tensile strength with respect to filler content.

of FA-filled HDPE composites has been decreased by employment of silane coupling agent as seen in Figure 3. Especially, up to $30 \%$ filler content, the decrease is very much lower for treated composites $(5.5 \%$ at $30 \%$ filler loading) than untreated ones $(21.0 \%$ at $30 \%$ filler loading). After $30 \%$ loading, the decrease for treated composites is in a sharper manner. Since tensile strengths of treated and untreated FA composites are higher than that of CC composites, FA can replace CC in terms of tensile strength. Increase in tensile strength for the silane-treated FA composites can be explained by better adhesion between filler and matrix. Without a coupling agent, the only adhesion mechanism is interdiffusion. Silane coupling agents yield to hydrogen and covalent bonding between $\mathrm{OH}$ groups of filler and polysiloxanes formed by hydrogenation of silanes. ${ }^{16,17}$

The Pukanszky model was also applied to CC, treated, and untreated FA-filled composites to determine the interaction parameter B. $B$ parameter was cal-

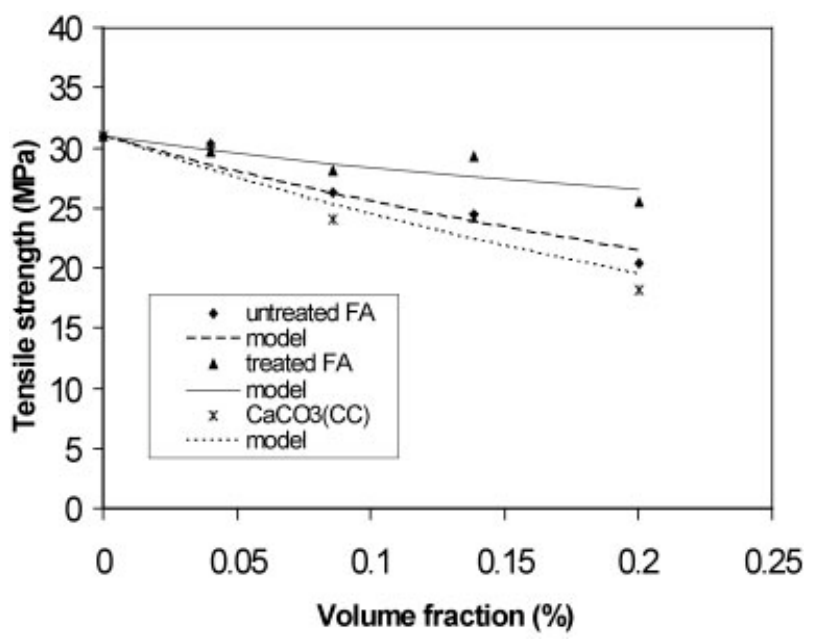

Figure 4 Comparison of experimental and theoretical values calculated by Pukanszky model.

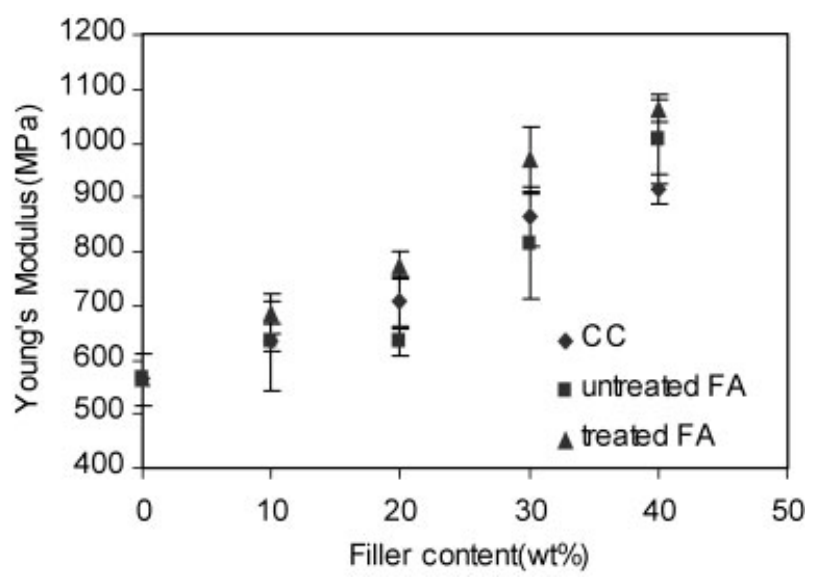

Figure 5 Variation of Young's modulus with respect to filler content.

culated as $0.396,1.306$, and 2.368 for CC, untreated, and treated FA composites, respectively. Comparison of $B$ values of treated and untreated FA composites clearly indicated that employment of silane treatment increased $B$ values. Consequently, adhesion between filler and matrix was greatly enhanced. Figure 4 shows the comparison of experimental data with Pukanszky model for three different composites as a function of volume fraction. As seen in Figure 4, experimental data is well correlated by the Pukanszky model.

Figure 5 shows the influence of surface treatment and filler loading on the Young's modulus of the composites. Young's modulus of all composites tended to increase with increasing filler content as observed in Figure 5. At 40\% loading, the increase in Young's modulus of the composites was $62.2 \%$ for CC, $78.5 \%$ for untreated FA, and $88.0 \%$ for treated FA. In fact, this property strongly depends on filler content, since fillers restrict deformation capacity of polymers in the elastic zone. Better adhesion between

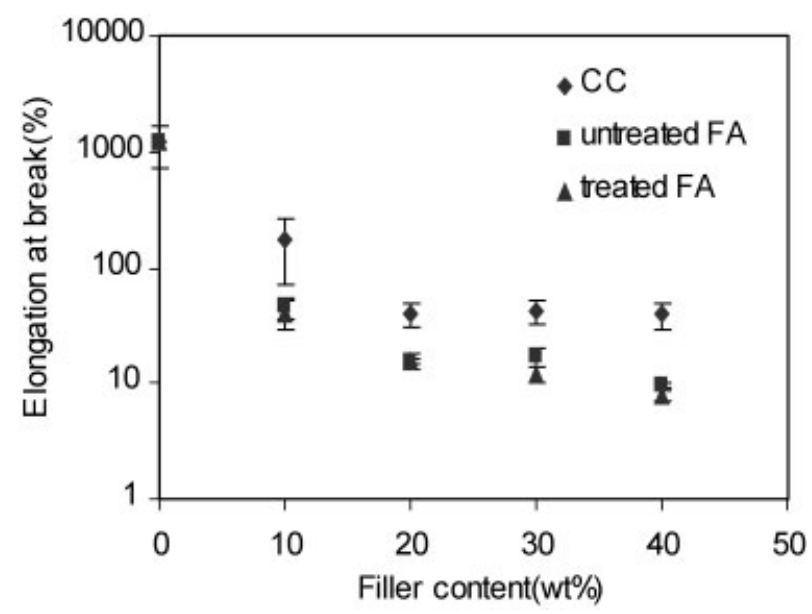

Figure 6 Variation of elongation at break with respect to filler content. 

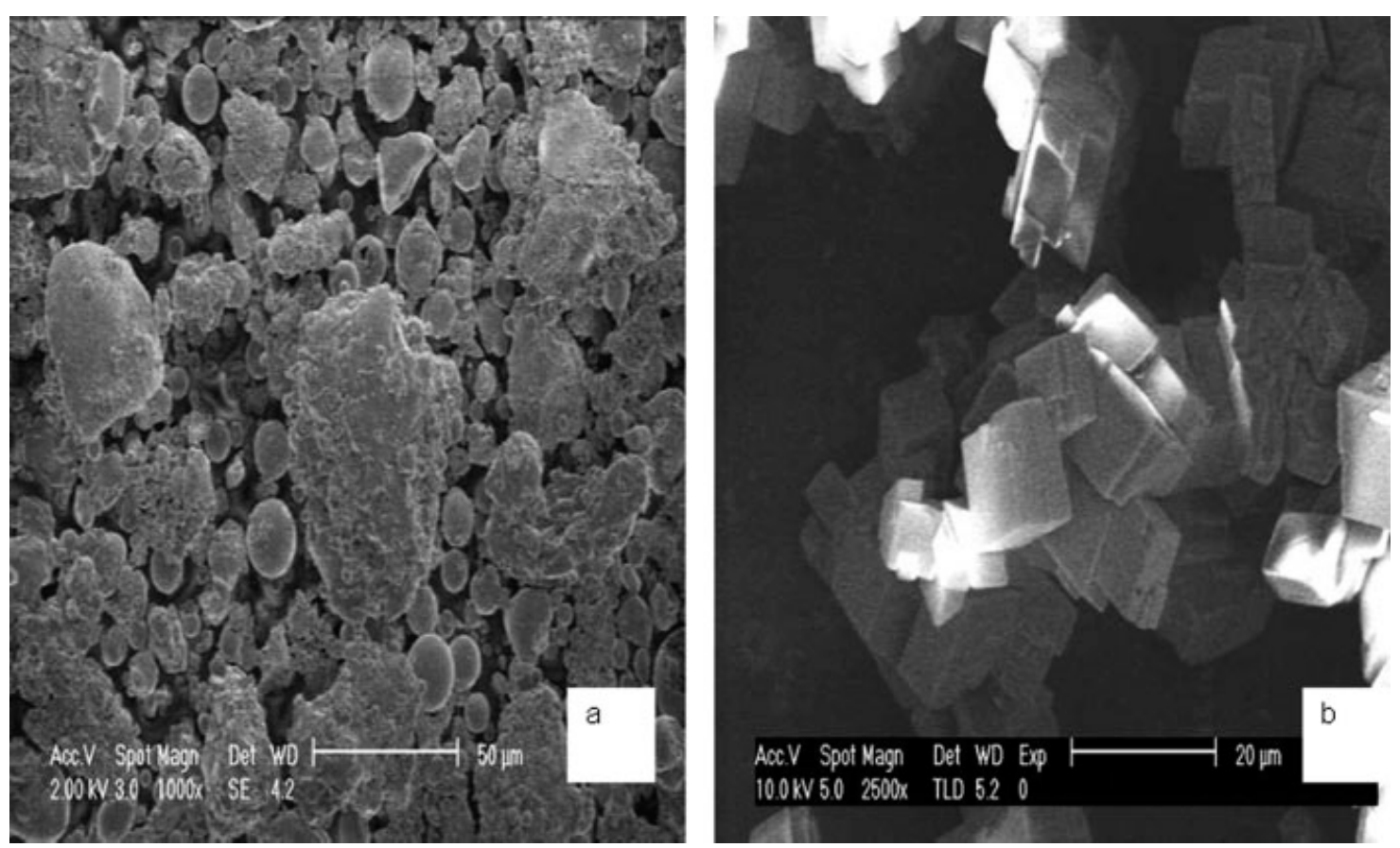

Figure 7 SEM micrographs of FA (a) and CC (b) particles.

FA filler and matrix with silane treatment provides more restriction to the deformation capacity of the polymer, and therefore increases Young's modulus.
Another important parameter affecting Young's modulus is the dispersion of filler in the matrix. Better dispersion yields to more restriction of the matrix which,
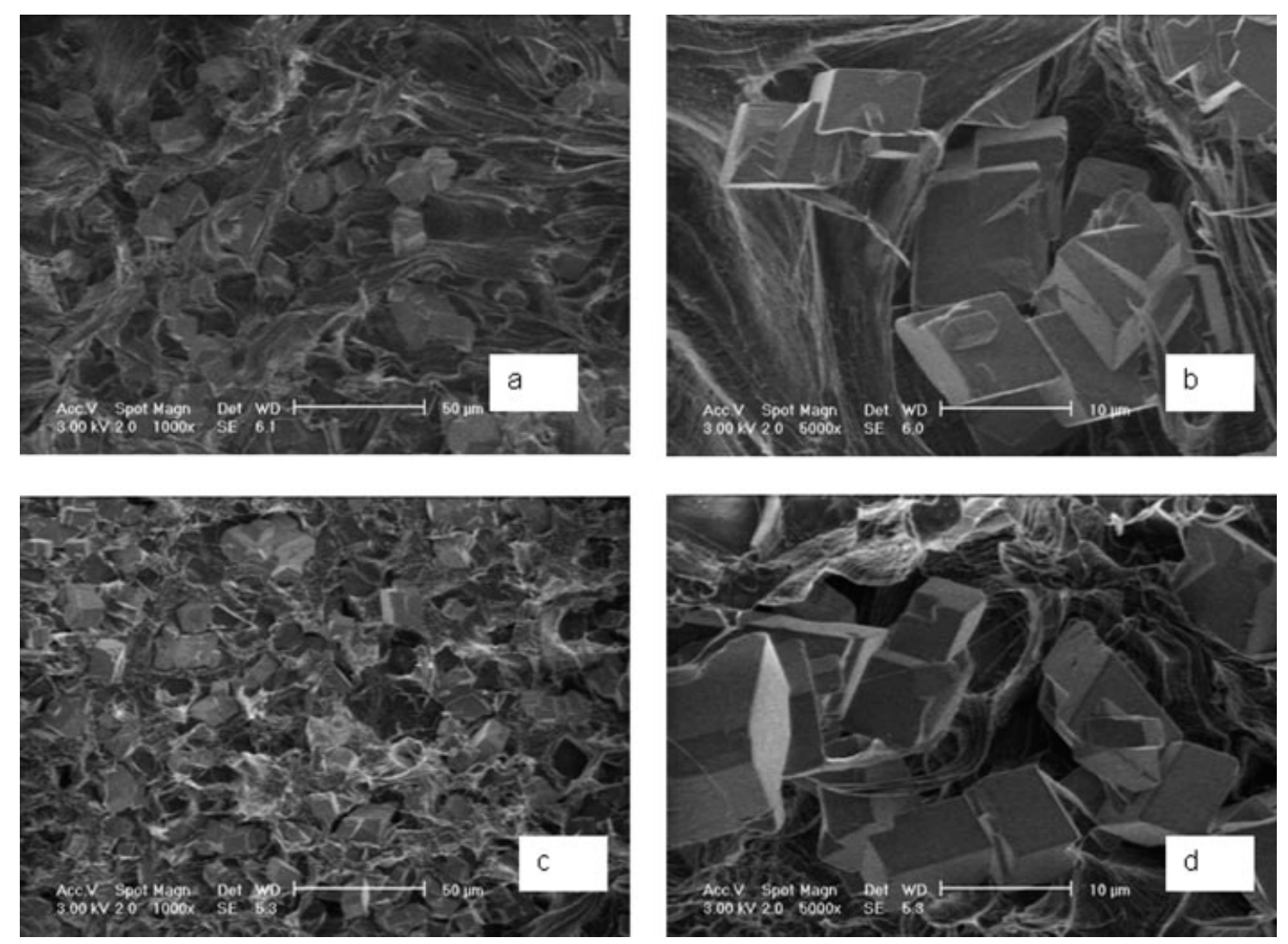

Figure 8 SEM micrographs of the fracture surfaces of HDPE-CC composites containing $(\mathrm{a}, \mathrm{b}) 30 \mathrm{wt} \% \mathrm{CC}$ and (c,d) $40 \mathrm{wt} \% \mathrm{CC}$. 
in turn increases Young's modulus. It can be concluded that FA-filled HDPE composite has higher Young's modulus than CC-filled HDPE composite at high filler loadings both for treated and untreated FA composites.

The effect of silane coupling agent and filler loading on the elongation at break of the composites is shown in Figure 6. Elongation at break of all composites decreases drastically when fillers were introduced to HDPE matrix. The decrease is higher for FA-filled composites compared with CC-filled composites. This can be attributed to the fact that, FA particles are more rigid than $\mathrm{CC}$, causing low flexibility of the polymer matrix. Also high particle size (up to $108 \mu \mathrm{m}$ ) of FA would cause more stress concentrations. The stress concentrations would be responsible for catastrophic breakage of the composites at low strains. In the presence of silane coupling agent, there is a slight decrease in elongation at break ( 9.7 and $7.7 \%$ for untreated and treated FA composite, respectively, at $40 \%$ filler loading). Better adhesion between filler and matrix would cause more restriction of the polymer and elongation would decrease accordingly.

\section{Morphological properties}

The morphology of the fillers and the effect of surface treatment on the interface between HDPE and FA on the fracture surface of composites were stud- ied by examining the fracture surfaces of tensiletested composites by SEM. Figure 7 illustrates the scanning electron micrographs of $\mathrm{CC}$ and FA particles. As seen in Figure 7(a), FA consists of unporous spheres and irregular shaped porous particles. Particle size of porous particles are greater than unporous spheres. CC has an isotropic, cube-shaped crystal structure with particle size varying between 4 and $15 \mu \mathrm{m}$ [Fig. 7(b)].

Figures 8(a-d) illustrate 1000 and 5000 times magnified electron micrographs of fracture surfaces of tensile-tested composites containing 30 and $40 \mathrm{wt} \%$ $\mathrm{CC}$, respectively. The weak interface between CC and HDPE can be clearly seen from the electron micrographs in Figure 8(a). CC particles are not embedded in the polymer matrix due to debonding of the fillers from the matrix. Low interfacial adhesion is the reason for debonding between filler and matrix. Low interfacial adhesion leads to low stress transfer from matrix to the filler, which is the cause of decrease in tensile strength with increasing filler loading. In general, filler is well dispersed in the matrix, even at high filler loadings, but agglomeration of the particles can be observed to some degree. Agglomeration of particles is greater in $40 \mathrm{wt} \%$-filled composites than in $30 \mathrm{wt} \%$ filled composites, which is depicted in Figures $8(\mathrm{~b}-\mathrm{d})$. Plastic deformation of HDPE fibrils around CC particles could be observed. Plastic deformation is relatively higher in $30 \mathrm{wt} \%$-filled composites than in
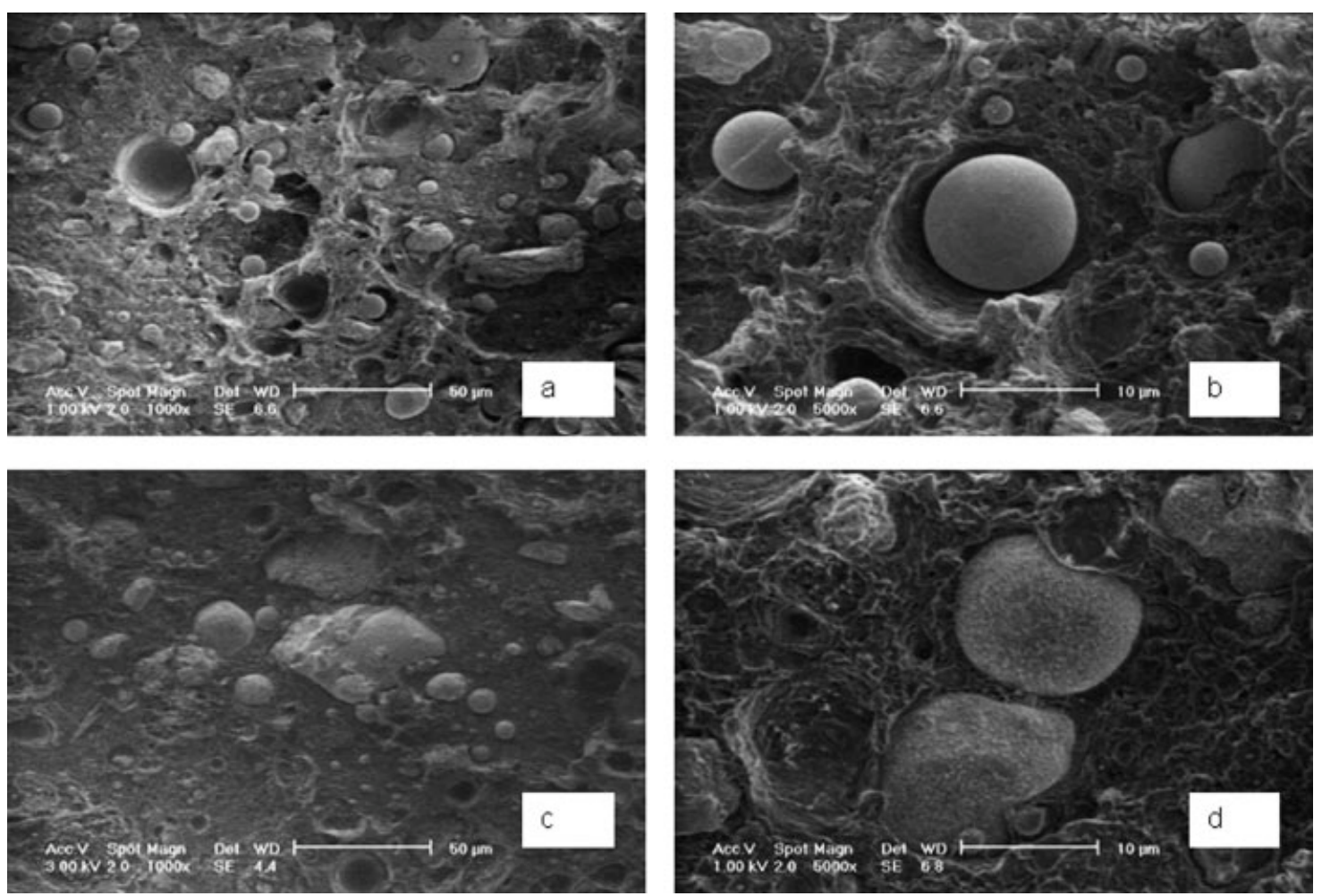

Figure 9 SEM micrographs of the fracture surfaces of HDPE-FA composites containing 30 wt \% FA (a,b) untreated and $(c, d)$ silane-treated. 
$40 \mathrm{wt} \%$-filled ones. This explains lower strain at break values with increasing loading.

Figures $9(\mathrm{a}-\mathrm{d})$ show the fracture surfaces of untreated and treated FA-filled composites at $30 \mathrm{wt} \%$ loading. The 1000 times magnified electron micrographs of fracture surface [Figs. $9(\mathrm{a}, \mathrm{c})$ ] illustrate that filler is well dispersed in the matrix without agglomeration of the particles both for treated and untreated composites. Fibrils of the matrix due to plastic deformation of the matrix could not be observed for FAfilled composites. Catastrophic failure of the matrix after yielding is the cause for lower strain at break values compared to CC composites. This effect can be explained by higher rigidity of FA particles than CCfilled composites, providing a more brittle characteristic to the composite. The effect of silane treatment on the interfacial adhesion of FA-filled composites can be seen more clearly in Figures 9(b,d). It was clearly observed that silane-treated fillers were well embedded in the matrix with matrix coverage around and on the fillers, whereas untreated fillers were not covered with the matrix and there are voids around the fillers. Untreated fillers were more easily pulled out of the matrix than treated ones, when a tensile stress is applied to the composites. All these observations prove that silane treatment improved interfacial adhesion between filler and matrix, by either chemical or physical bonding between polar groups of filler and coupling agent, leading to better tensile strength compared to untreated composites. Electron micrographs of the fracture surface of $40 \mathrm{wt} \%$-filled untreated and treated FA composites were shown Figures $10(a-d)$. When it was compared with $30 \mathrm{wt} \%$ filled composites, it was observed that both composites exhibit good dispersion of particles in the matrix without agglomeration. Better interfacial adhesion for silane-treated composites could also be observed for 40 wt \%-filled composites. All these observations relating to effect of silane treatment on the interface is consistent with mechanical test results and it is obvious that there is a close relationship between interfacial adhesion properties and
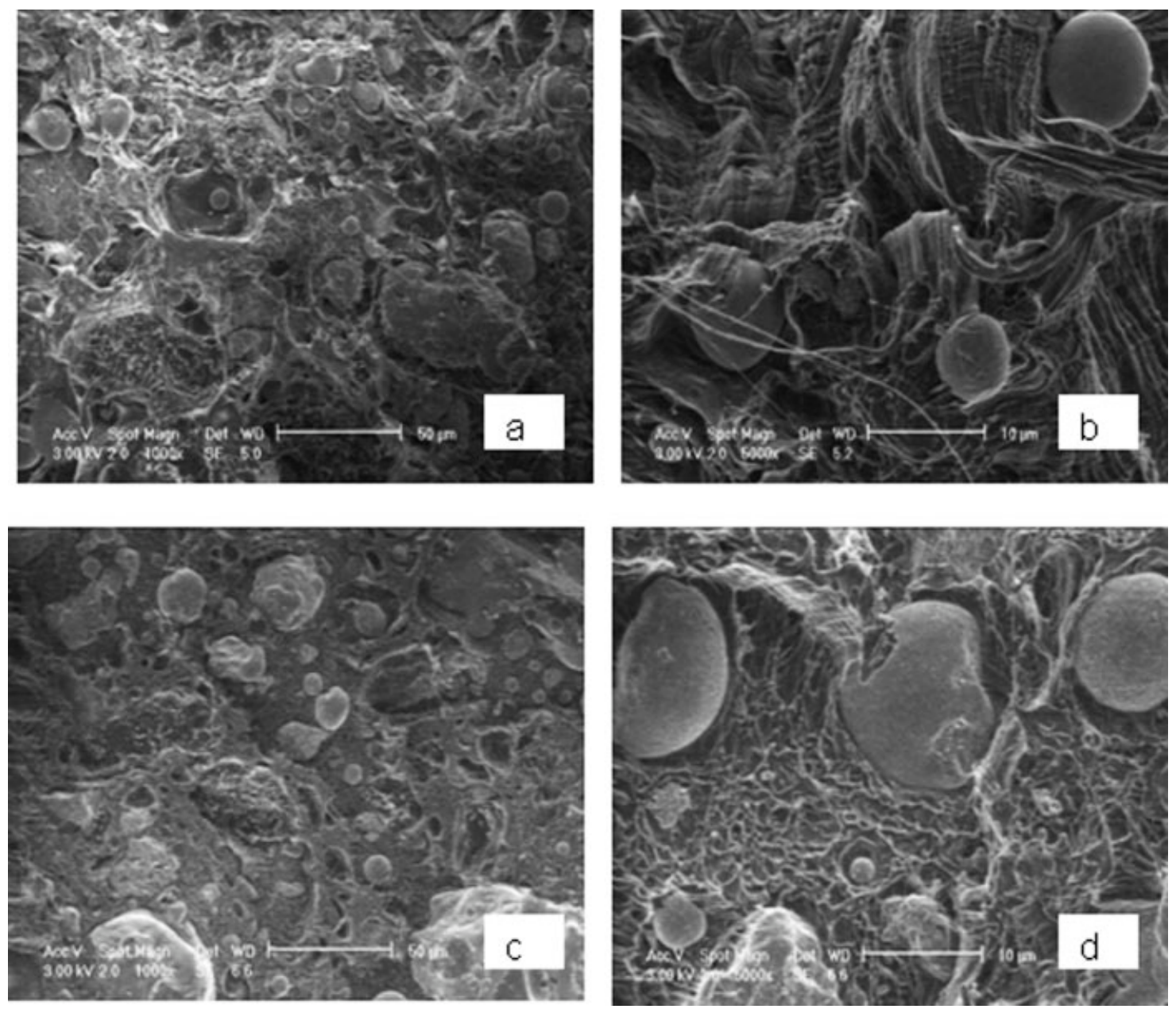

Figure 10 SEM micrographs of the fracture surfaces of HDPE-FA composites containing 40 wt \% FA (a,b) untreated and (c,d) silane-treated. 
mechanical properties, especially tensile strength and Young's modulus.

\section{CONCLUSIONS}

In the present study, the effect of filler loading and surface treatment on the mechanical and morphological properties of calcium carbonate (CC)- and fly ash (FA)filled recycled HDPE composites were investigated and compared to each other. The effect of silane treatment of FA on the mechanical and morphological properties of FA-filled recycled HDPE composites was studied. It was found that silane treatment indicated significant improvements on the mechanical properties of the HDPE-FA composites. The improvement with silane treatment of FA was also confirmed by Pukanszky Model. FA-filled HDPE composites have comparable mechanical properties with the CC-filled composites, but silane treatment of FA has a positive impact on mechanical properties of FA-filled composites compared to untreated FA composites and CCfilled composites. SEM studies have given direct evidence of better interfacial adhesion between FA filler and HDPE matrix, which is an indicator of higher mechanical properties achieved via silane treatment. Conclusively, it was found that FA can replace $\mathrm{CC}$ as a filler for HDPE composites.

\section{References}

1. Cavaliere, F.; Padella, F. Waste Manage 2002, 22, 913.

2. Dintcheva, N. T.; Jilov, N.; La Mantia, F. P. Polym Degrad Stab 1997, 57, 191

3. Nikartaus, C.; Papaspyrides, C. D.; Pfaendner, R. Polym Degrad Stab 2000, 70, 189.

4. Boldizar, A.; Jansson, A.; Gevert, T.; Möller, K. Polym Degrad Stab 2000, 68, 317.

5. Albano, C.; Gonzales, J.; Ichazo, M.; Rosales, C.; Urbina de Navarro, C.; Parra, C. Compos Struct 2000, 48, 49.

6. Avila, A. F.; Duarte, M. V. Polym Degrad Stab 2003, 80, 373.

7. Huang, X.; Hwang, J. Y.; Gillis, J. M.; J Miner Mater Character Eng 2003, 2, 11.

8. Colom, X.; Carrasco, F.; Pages, P.; Canavate, J. Compos Sci Technol 2003, 63, 161.

9. Metin, D.; Tihminlioğlu, F.; Balköse, D.; Ülkü, S. Compos A 2004, 35, 23.

10. Li, Y.; White, D. J.; Peyton, R. L. Resour Conserv Recycl 1998, $24,87$.

11. Bartczak, Z.; Argon, A. S.; Cohen, R. E.; Weinberg, M. Polymer 1999, 40, 2347.

12. Kwon, S.; Kim, K. J.; Kundu, P. P.; Kim, T. J.; Lee, Y. K.; Lee, B. H.; Choe, S. Polymer 2002, 43, 6901.

13. Suwanprateeb, J. Compos A 2000, 31, 353.

14. Alkan, C.; Arslan, M.; Cici, M.; Kaya, M.; Aksoy, M. Resour Conserv Recycl 1995, 13, 147.

15. Pukanszky, B.; Fekete, E. In Advances in Polymer Science; Jancar, J., Ed.; Springer: New York, 1999.

16. Jancar, J. Advances in Polymer Science; Springer: New York, 1999.

17. Hull, D.; Clyne, T. W. An Introduction to Composite Materials; Cambridge University Press: Cambridge, UK, 1996. 